\title{
A proposed methodology for nowcasting the demand and supply estimates of tourism activities
}

Tullio Buccellato, Dominic Webber and Sean White

Office for National Statistics

\section{Summary}

The main objective of this work is to produce up to date and frequent figures of the demand and supply sides of the tourism sector. Demand here refers to tourism consumption or expenditure, while supply refers to the output from tourism related industries. This is carried out to address one of the weaknesses of the Tourism Satellite Account (TSA), which is based on data from the System of National Accounts (SNA) which is published two years after the reference date. The requirement for timely and frequent figures for tourism demand and supply has emerged from all the main actors in the UK tourism sector: the national tourism boards, for example VisitEngland; Department for Culture, Media, and Sport (DCMS); and the nine regional development agencies (RDA).

\section{Introduction}

The production of statistically precise figures concerning the tourism sector is in itself a difficult task. Tourism is a sector that, unlike other sectors in the economy, is not characterised by a clear production function. Both the final good consumed by tourists and input used on their production are not clearly identifiable. International recommendations strongly advise the use of the TSA framework to tackle the difficulties of measuring tourism economic impact in the most complete fashion. The main feature of the TSA is to measure separately the demand components of tourism and the supply industries in the sector and to then reconcile them. This comprehensive reconciliation procedure allows measuring, sector-by-sector, the share of output produced in tourism related industries absorbed directly by tourists' demand. As a result of these characteristics the TSA represents the core part of the emerging integrated system of tourism statistics (ISTS) within ONS.

Experimental Tourism Satellite Account for the UK are published in this edition of the Economic \& Labour Market Review (ELMR) (see Buccellato et al 2010). This, as the name suggests, attempts to construct a TSA for the UK based on data sources from 2006. As mentioned in greater detail within that paper there are issues regarding the accuracy of some of the figures reported. Furthermore, the timeliness remains an unresolved issue. The construction of the TSA is a very 
complex procedure resulting from the synthesis of several data sources, some of which are largely out of date due to the demanding production process they have to undergo to be published.

Therefore, the most appropriate step forward is to nowcast ${ }^{1}$ some of the most relevant headline figures contained in the TSA. The main obstacle to overcome in this sense is to find alternative data sources to benchmark the headline figures both on the supply and on the demand side. In a perfect world it would have been possible to access data sources allowing for the construction of a monthly TSA with a three months delay with respect to the reference period. With this ideal objective in mind data sources allowing for the best compromise will be looked for. Or, stated differently, it will be attempted to solve one of the main drawbacks of the TSA within the TSA demand-supply framework. In this way the role of the TSA within the ISTS is further strengthened.

This article focuses mainly on proposing a methodology to nowcast tourism figures rather than actually attempting to produce up to date figures on demand and supply of the tourism sector. However, the current work represents an essential milestone towards the creation of a production system of up to date figures based on the TSA framework. As a result, it is shown how data availability allows obtaining nowcasted figures up to two quarters after the reference period.

The second section will provide a summarised background of the TSA framework, on which the content of this paper relies heavily. The third section outlines the methodology for nowcasting the demand and the supply side of tourism. The fourth section details the supply side, while the fifth section describes the overall results. The sixth and final section draws some general conclusions.

\section{A quick catch-up on the TSA framework}

Following and updating the 'First Steps project' ${ }^{2}$, the Tourism Intelligence Unit (TIU) has started setting up the framework for a UK TSA reflecting the most up to date international recommendations. The remainder of this document reports the details of this experimental TSA for the UK.

The measurement of tourism can be achieved in a twofold perspective - either as a demand side or as a supply side phenomenon. The demand side of the tourism sector refers to all the activities of visitors and their consumption behaviours. The supply side refers instead to the tourism related industries as indicated by international recommendations, shown in the first column of the table in Box 1. One of the main advantages of the TSA methodology is to allow for a reconciliation of the twofold nature of tourism measurement.

The TSA can be simply described as a collection of information ordered in 10 tables, six of which can be considered as core tables. The first three tables summarize the demand side information categorizing it respectively in inbound tourism expenditure, domestic tourism expenditure and outbound tourism expenditure ${ }^{3}$. The fourth table provides the total tourism expenditure summing up figures displayed in tables one and two. The fifth table contains supply side data and the sixth table reconciles demand and supply figures as displayed in table four and five respectively. The seventh table collects data concerning the employment in tourism industries. The eighth collects data on the tourism gross fixed capital formation of tourism industries and other industries. The 
ninth displays figures on tourism collective consumption by products and levels of government. The tenth and final table concludes showing the non-monetary indicators.

\section{Figure 1 Domestic supply and consumption of products, 2006}

$£$ billions

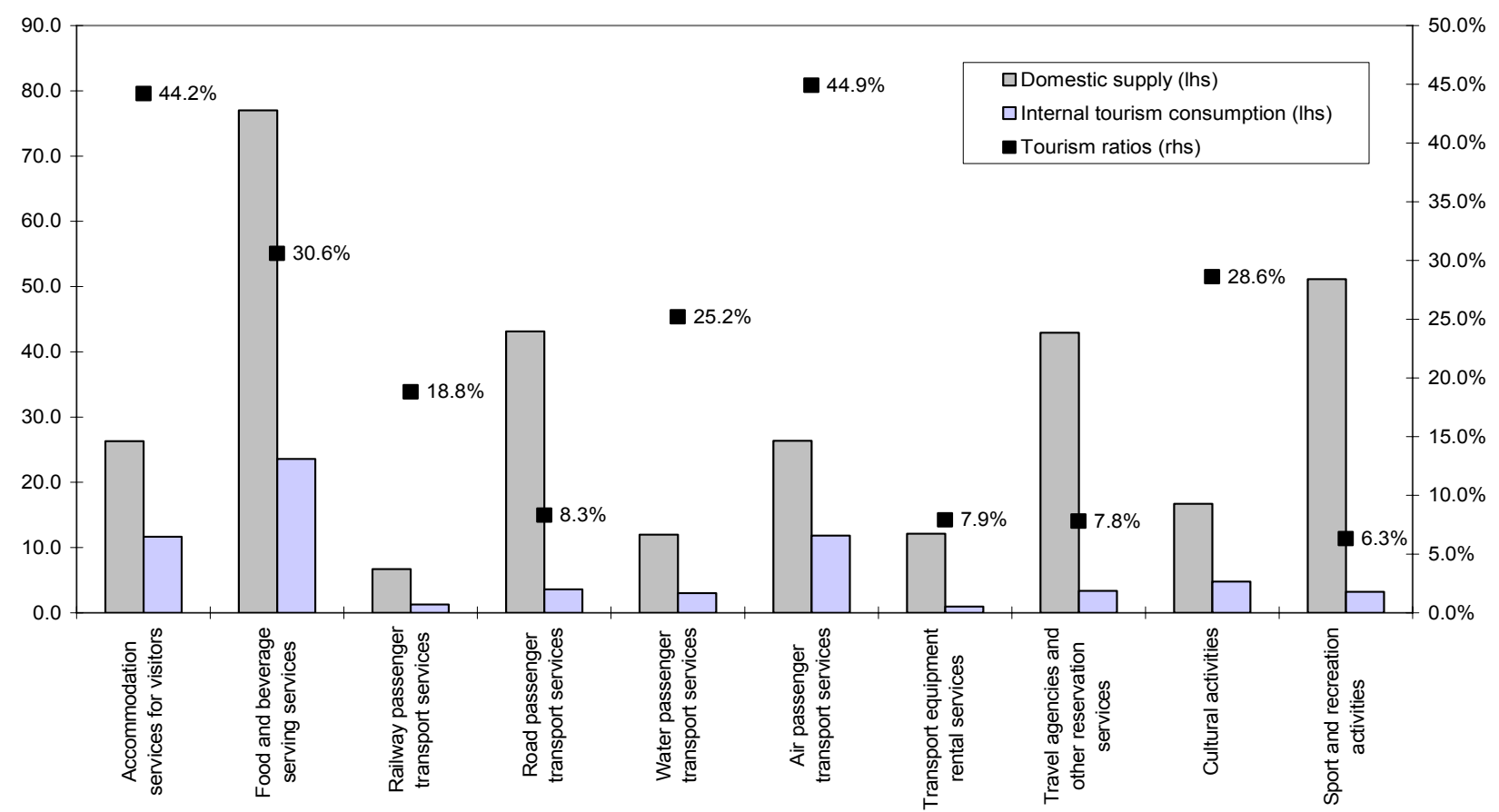

Product

Domestic supply (£

Internal tourism consumption ( $£$ billions)

Tourism ratios billions)

Accommodation services for visitors

\begin{tabular}{rcc}
26.3 & 11.6 & 44.2 \\
77.0 & 23.6 & 30.6 \\
6.7 & 1.3 & 18.8 \\
43.1 & 3.6 & 8.3 \\
12.0 & 3.0 & 25.2 \\
26.3 & 11.8 & 44.9 \\
12.1 & 1.0 & 7.9 \\
42.9 & 3.3 & 7.8 \\
16.7 & 4.8 & 28.6 \\
51.1 & 3.2 & 6.3 \\
$2,634.7$ & 30.9 & 1.2 \\
$2,949.0$ & 98.1 & 3.3 \\
\hline
\end{tabular}

Source: E-UKTSA 
In the construction of the experimental TSA for the UK (E-UKTSA) the focus is on the first six tables. This is where the process of reconciliation between demand and supply of tourism industries actually takes place (with the exclusion of Table 3 which contains outbound tourism expenditure so is not necessary for the final reconciliation of demand and supply). It is within this core part of the TSA framework that demand and supply of the tourism related industries are reconciled in the so-called demand-to-supply ratio (DSR). The importance of the DSR is based on the fact that it allows disentangling what share of the national economy is directly dependent upon tourism consumption and is a necessary step towards the computation of tourism direct gross value added (TDGVA).

Figure 1 summarises some highlights from Table 6 of the E-UKTSA. The three columns reported below the chart represent the reconciliation of supply and demand of tourism industries and the implied DSR. The chart in the upper part of the figure summarises the numbers at quick glance. The contents of Figure 1 will be crucial in the development of the methodology that, ultimately, will provide a dynamic version of both columns 1 and 2 thanks to the tourism DSRs reported in column 3.

\section{A simple methodology to nowcast the E-UKTSA implied figures}

This section gives details of the methodology to nowcast the demand and supply aspects of tourism.

The domestic demand of tourism can be broadly divided into two main parts - inbound and domestic visitors' expenditure. Both these components can be further classified into excursionists and overnight visitors. An additional component of tourism consumption is represented by the domestic expenditure of resident visitors travelling abroad (RVTA). This represents the expenditure of domestic residents in their domestic economy on services for outbound travel. It is characterised by expenditure on UK-based carriers and travel agencies.

The focus now turns to a review of the available data sources and the way these could be used to benchmark the annual figures contained in the national TSA.

The overall procedure to estimate timely and frequent time series for each of the components of tourism demand can be articulated in four steps. First, total tourism demand is estimated. Second, for inbound and domestic overnight tourists' expenditure direct use of available time series is made to benchmark the correspondent annual figures of the E-UKTSA. Third, an estimate of the domestic expenditure of resident visitors travelling abroad is obtained. Finally, an estimate of excursionists expenditure is obtained as the net of total demand and all the other components estimated in the previous steps.

Obtaining a quarterly time series for the total demand of tourism is rendered quite straightforward by the availability of a quarterly time series for the total UK gross value added (GVA). Using the tourism demand to total supply ratio (DSR), calculated in Table 6 of the TSA, allows for the following estimation procedure 
Total_ Demand ${ }_{t}=\operatorname{DSR}_{2006}^{\text {E-UKTSA }} \times$ Total_Supply

Having obtained quarterly estimates of the total demand of the tourism economy over the time span 2006 Q1-2009 Q1, the next step is to break it down into its main components.

The International Passenger Survey (IPS) collects spend and volume data for inbound tourists. This data source is both frequent (monthly), and timely (approximately six weeks after the reference period). The IPS measures both excursionists' and overnight visitors' inbound expenditure. Timely and frequent data are also available for the overnight component of domestic tourists. The UK Tourism Survey (UKTS) implemented by Taylor Nelson Sofres (TNS) and funded by the national tourist boards provides quarterly estimates for the total overnight domestic tourism expenditure. Hence, this data source can fit the purpose of benchmarking the national figure reported in the E-UKTSA with a relatively high degree of accuracy.

More problematic is to find a way to benchmark the annual figures for the expenditure of resident visitors travelling abroad (RVTA). The IPS collects volume and expenditure data for these visitors while they are abroad. However, at present, no survey details the UK-based spending of this group of tourists. To tackle the problem of generating up-to-date figures for the spending in the UK of RVTA involves benchmarking the 2006 figures to the volume of RVTA. In formula,

$$
R V T A_{t}=\left(1+r_{t-1, t}^{i}\right) R V T A_{t-1}
$$

where RVTA $A_{t}$ represents estimated quarterly time series for the expenditure of residents travelling abroad at time $t$. The rate of growth of outbound tourist volumes between $t$ and $t-1$ is represented by $r_{\mathrm{t}-1, \mathrm{t}}$. Estimates obtained from equation (2) heavily rely on the assumption that the outbound tourist's volume and the domestic expenditure of RVTA enjoy the same time series properties.

The last step of the procedure consists of estimating the quarterly time series of excursionists' expenditure as a residual from the total demand. This can now be easily achieved subtracting the time series obtained in the second and third steps of our procedure from the estimate for total demand obtained through equation (1). This approach nonetheless requires that the series are seasonally adjusted to avoid the potential that the newly estimated series exhibit an artificial seasonal pattern with respect to the other main demand components.

The supply side is addressed adopting a bottom-up approach. This involves nowcasting the supply of each tourism industry individually and simply summing up to obtain the total supply of the tourism industries. This is achieved by benchmarking E-UKTSA industry supply figures, as reported in Table 6 to a quarterly non-seasonally adjusted (NSA) GVA index series for each tourism industry. Measured in current prices, these series are available from internal ONS 
resources. Each series is weighted according to the importance of each component in an industry. The components of each industry are summarised in Box 1.

\section{Box $1 \quad$ Tourism industries and their components}

\begin{tabular}{|c|c|}
\hline Industry & Components \\
\hline \multirow{3}{*}{ Accommodation services for visitors } & Hotels \\
\hline & Camping etc \\
\hline & Restaurants \\
\hline \multirow[t]{2}{*}{ Food and beverage serving services } & Bars \\
\hline & Canteens \\
\hline \multirow[t]{2}{*}{ Railway passenger transport services } & Trains \\
\hline & Other scheduled passenger land transport \\
\hline \multirow[t]{2}{*}{ Road passenger transport services } & Taxi operation \\
\hline & Other passenger land transport \\
\hline \multirow{2}{*}{ Water passenger transport services } & Sea and coastal passenger water transport \\
\hline & Inland water transport \\
\hline Air passenger transport services & Scheduled air transport \\
\hline \multirow{2}{*}{ Transport equipment rental services } & Renting of Automobiles \\
\hline & Renting of other transport equipment \\
\hline \multirow[t]{3}{*}{ Travel agencies and other reservation services } & $\begin{array}{l}\text { Activities of travel agencies and tour operators; tourist assistance activities } \\
\text { n.e.c. }\end{array}$ \\
\hline & Motion pictures and video activities \\
\hline & Artistic and literary creation and interpretation \\
\hline \multirow[t]{4}{*}{ Cultural services } & $\begin{array}{l}\text { Operation of arts facilities ; fair and amusement park activities ; other } \\
\text { entertainment activities n.e.c. }\end{array}$ \\
\hline & Library, archives, museums and other cultural activities (market) \\
\hline & Library, archives, museums and other cultural activities (non-market) \\
\hline & Sporting activities and other recreational activities n.e.c \\
\hline \multirow[t]{2}{*}{ Sports and recreational services } & Sporting activities and other recreational activities n.e.c \\
\hline & Gambling and betting activities \\
\hline
\end{tabular}

n.e.c. not elsewhere classified

The final stage in the process is to nowcast 'Other consumption products'. This is realized by benchmarking the corresponding E-UKTSA figure to a non-seasonally adjusted GVA index series for the whole economy, again measured at current prices.

Formally, the method for nowcasting the tourism industries is as follows 
$Y_{i, t}=\left(1+\left(\sum_{j=1}^{n} w_{j}^{i} \cdot r_{j}^{i}\right)\right) \cdot Y_{i, t-1}$

where $Y_{i, t}$ is the time series for the tourism industry $\mathrm{i}$ at quarter $\mathrm{t}$ with $\mathrm{t}=2002 \mathrm{Q} 1,2002 \mathrm{Q} 2, . ., 2009$ Q1 refers to the quarter and $i=1,2, \ldots, 11 . W_{j}$ represents the weight of the GVA component $j$ part of the industry i. $r_{j}$ represents the rate of growth in GVA of component $j$.

Data availability allows obtaining nowcasted figures up to two quarters after the reference period. Box 2 summarises the above mentioned data sources used in our methodology and their respective timeliness.

\section{Box 2 The main variables and their respective data sources used in this analysis}

\begin{tabular}{|c|c|c|c|c|}
\hline Variable & Survey & Source & Frequency & Timeliness \\
\hline Inbound expenditure & $\begin{array}{c}\text { International Passenger } \\
\text { Survey }\end{array}$ & $\begin{array}{l}\text { Office for National } \\
\text { Statistics }\end{array}$ & Monthly & $\begin{array}{l}6 \text { weeks after the } \\
\text { reference month }\end{array}$ \\
\hline Outbound volumes & $\begin{array}{l}\text { International Passenger } \\
\text { Survey }\end{array}$ & $\begin{array}{l}\text { Office for National } \\
\text { Statistics }\end{array}$ & Monthly & $\begin{array}{l}6 \text { weeks after the } \\
\text { reference month }\end{array}$ \\
\hline Overnight Visitors expenditure & UK Travel Survey & $\begin{array}{c}\text { Taylor Nelson and } \\
\text { Sofres }\end{array}$ & Monthly & $\begin{array}{l}12 \text { weeks after the } \\
\text { reference month }\end{array}$ \\
\hline Gross Value Added series & Internal ONS resources & $\begin{array}{l}\text { Office for National } \\
\text { Statistics }\end{array}$ & Quarterly & $\begin{array}{l}4 \text { weeks after the } \\
\text { reference quarter }\end{array}$ \\
\hline
\end{tabular}

\section{Results}

This section is devoted to presenting the results implied by the methodology. The presentation of this will follow the TSA framework, highlighting first the demand followed by the supply side separately, and then their direct reconciliation.

Figure 2 presents the nowcasted series of the four components that compose the tourism demand which are essentially proposing a dynamic version of the headline figures contained in Table 4 of the E-UKTSA. The estimated series for the domestic expenditure of RVTA looks fairly stable over time with a slight slowdown towards the end of the series reflecting the fall of outbound tourism that corresponds with the start of the international crisis. In the case of the UK the crisis has induced a sharp depreciation of the sterling and this, perhaps, explains partly at least why the inbound expenditure has been moving in the opposite direction with respect to the expenditure of outbound 
expenditure. For more detail on the impact of the recession on tourism please refer to an earlier paper from the TIU (see Webber et al 2010).

\section{Figure 2 Nowcasts of the main components of tourism demand, 2006 Q1 - 2009 Q1}

$£$ billions

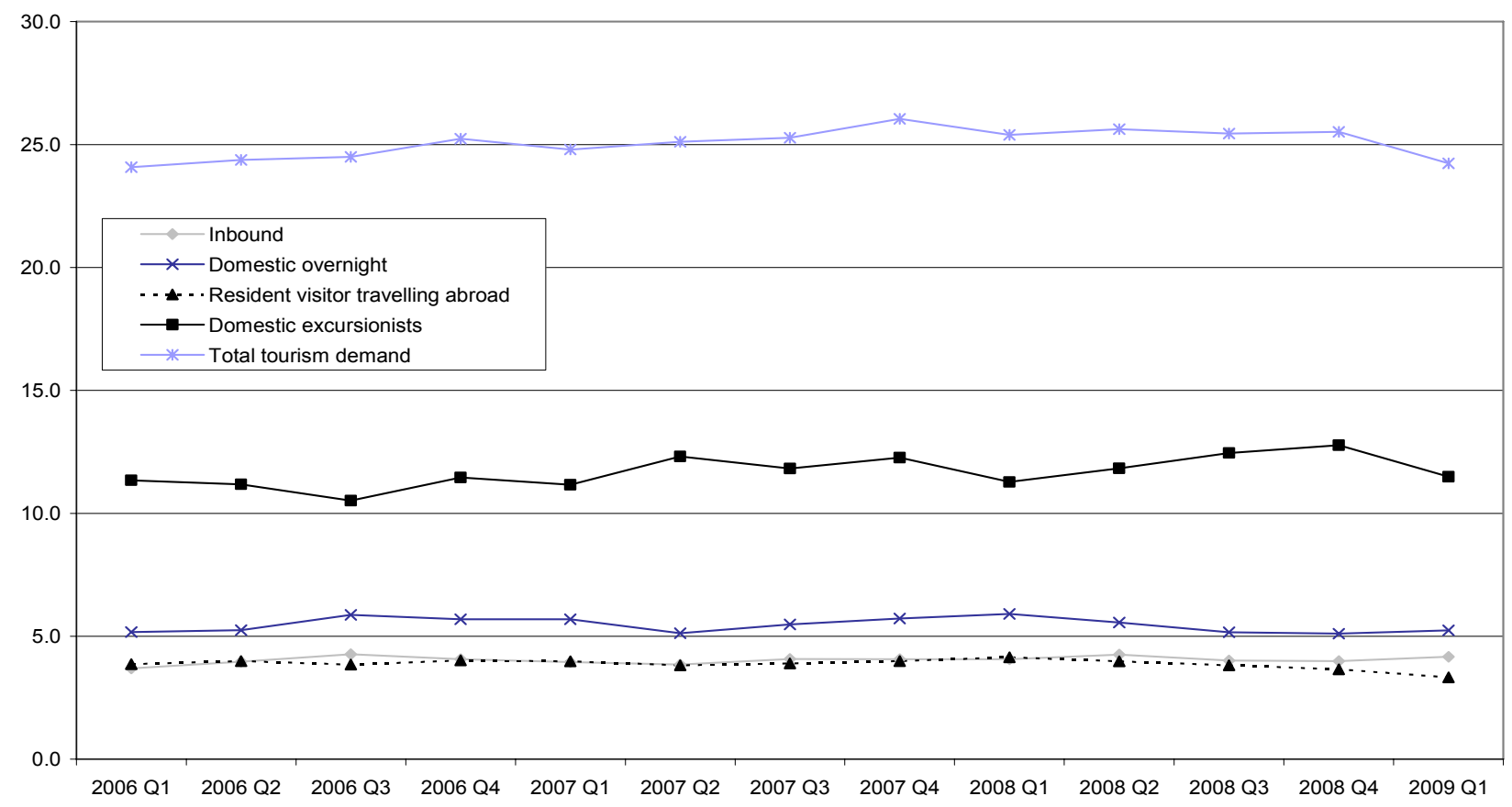

\begin{tabular}{lccccc}
\hline Time & Inbound & Domestic overnight & $\begin{array}{c}\text { Resident visitor travelling } \\
\text { abroad }\end{array}$ & $\begin{array}{c}\text { Domestic } \\
\text { excursionists }\end{array}$ & $\begin{array}{c}\text { Total tourism } \\
\text { demand }\end{array}$ \\
\hline 2006 Q1 & 3.7 & 5.2 & 3.9 & 11.3 & 24.1 \\
2006 Q2 & 4.0 & 5.2 & 4.0 & 11.2 & 24.4 \\
2006 Q3 & 4.3 & 5.9 & 3.8 & 10.5 & 24.5 \\
2006 Q4 & 4.1 & 5.7 & 4.0 & 11.5 & 25.2 \\
2007 Q1 & 4.0 & 5.7 & 4.0 & 11.2 & 24.8 \\
2007 Q2 & 3.9 & 5.1 & 3.8 & 12.3 & 25.1 \\
2007 Q3 & 4.1 & 5.5 & 3.9 & 11.8 & 25.3 \\
2007 Q4 & 4.1 & 5.7 & 4.0 & 12.3 & 26.0 \\
2008 Q1 & 4.1 & 5.9 & 4.1 & 11.3 & 25.4 \\
2008 Q2 & 4.3 & 5.6 & 4.0 & 11.8 & 25.6 \\
2008 Q3 & 4.0 & 5.2 & 3.8 & 12.5 & 12.8 \\
2008 Q4 & 4.0 & 5.1 & 3.7 & 11.5 & 25.5 \\
2009 Q1 & 4.2 & 5.2 & 3.3 & & 25.5
\end{tabular}

Sources: E-UKTSA, International PASSENGER Survey (average 2006-2008), UK Tourism Survey (average 20062008), Great Britain Day Visit Survey 2002/3, English Leisure Visits Survey 2005 and Authors' calculations. 
Excursionist expenditure is the series which has required the heaviest estimation procedure. This could be a contributing factor in explaining the slightly higher volatility exhibited by the series. It is interesting to highlight the opposing behaviour of this series in relation to the economic crisis with respect to the domestic overnight visitor component. Domestic overnight visitor expenditure has increased perhaps because it represents the direct substitute of outbound tourism, which has fallen quite sharply over the same period. Overall, tourism related consumption in the UK appears to be fairly stable exhibiting a slightly positive trend with total consumption of tourists passing from around $£ 98$ billion in 2006 to $£ 101$ billion in 2007 to $£ 102$ billion in 2008 . The first quarter of 2009 suggests that the trend could revert, possibly due to the current economic crisis.

Figure 3a displays the evolution of the supply side dimension of tourism over time. It should be noticed in Figure 3 that we are referring to the same time trend that we have reported for the demand side series reported in Figure 2. In this sense it is worth insisting on the fact that the total demand cannot be directly derived from available data sources, but instead employs an estimation procedure based on the data sources for the supply side of tourism and the DSR of 3.3 per cent calculated in the E-UKTSA.

\section{Figure 3a The supply of tourism industries, 2006 Q1 - 2009 Q1}

$£$ billions

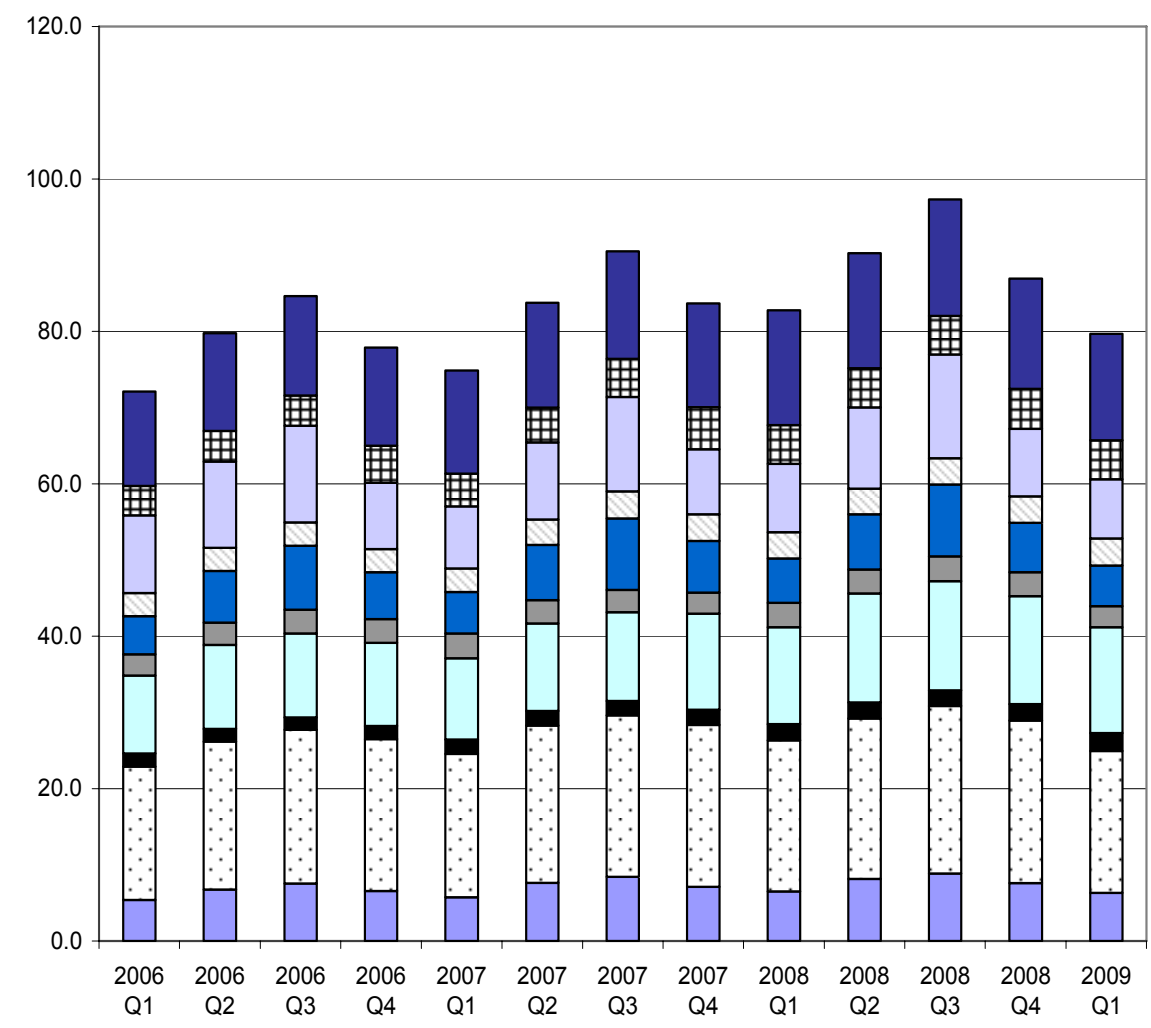

$\square$ Sports and recreational services

$\square$ Cultural services

$\square$ Travel agencies and other reservation services

$\square$ Transport equipment rental services

$\square$ Air passenger transport services

$\square$ Water passenger transport services

$\square$ Road passenger transport services

Railway passenger transport services

$\square$ Food and beverage serving services

$\square$ Accommodation services for visitors

Source: Quarterly Gross Value Added series, ONS 
The higher accuracy of supply side data allows for the breakdown of the total supply in its components over time. The proportion of the components and their respective shares in the total supply of tourism related products remains fairly stable over time with food and beverage, road passenger transport and air transport exhibiting the largest shares.

Figure $\mathbf{3 b}$ completes the supply side analysis showing the seasonal patterns of the figures involved. Some series, such as hotel and accommodation, travel agencies, air passenger transport and even food and beverage to some extent have very similar seasonal patterns. This might result from the higher dependence on actual tourism consumption of these sectors as opposed to road and rail passenger transport or sports and recreation services, for example. One would normally expect that tourism demand peaks during the third quarter of the year during the summer period.

\section{Figure 3b The supply of tourism industries, 2006 Q1 - 2009 Q1}

$£$ billions

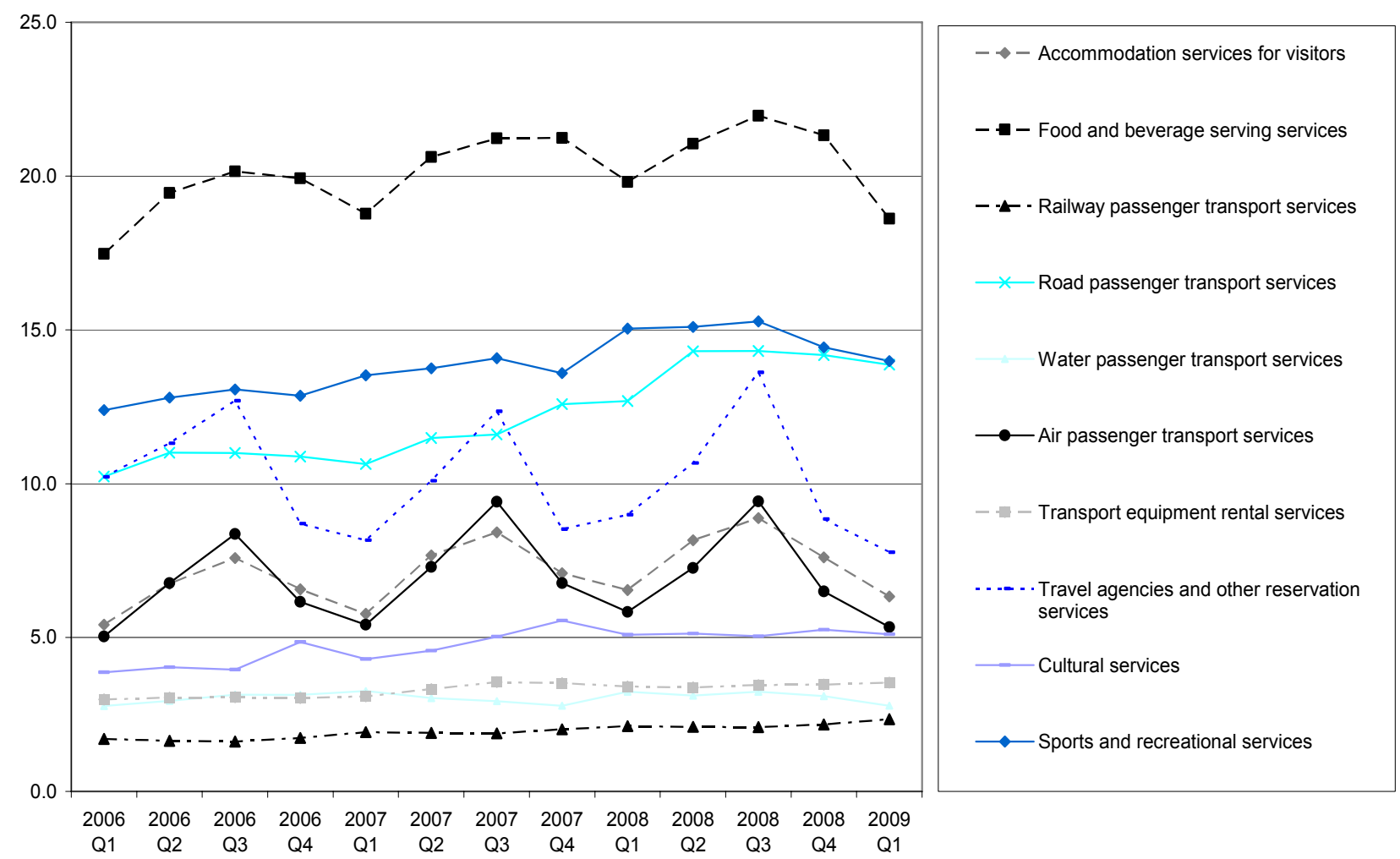

Source: Quarterly Gross Value Added series, ONS

The final step of the analysis consists of using the main demand-supply reconciliation results contained in Table 6 the E-UKTSA in order to have a dynamic breakdown of tourist expenditure in its main components. Figure 4 illustrates the results of this procedure both in a numerical and in a graphical way. By construction, the shares of each of the industries, in terms of total economy supply, remain constant over time and equal to the ones displayed in Figure 2; the seasonal pattern will be the same of the total supply of tourism related products. 
Figure 4 Estimates of tourist expenditure and its main components

$£$ billions

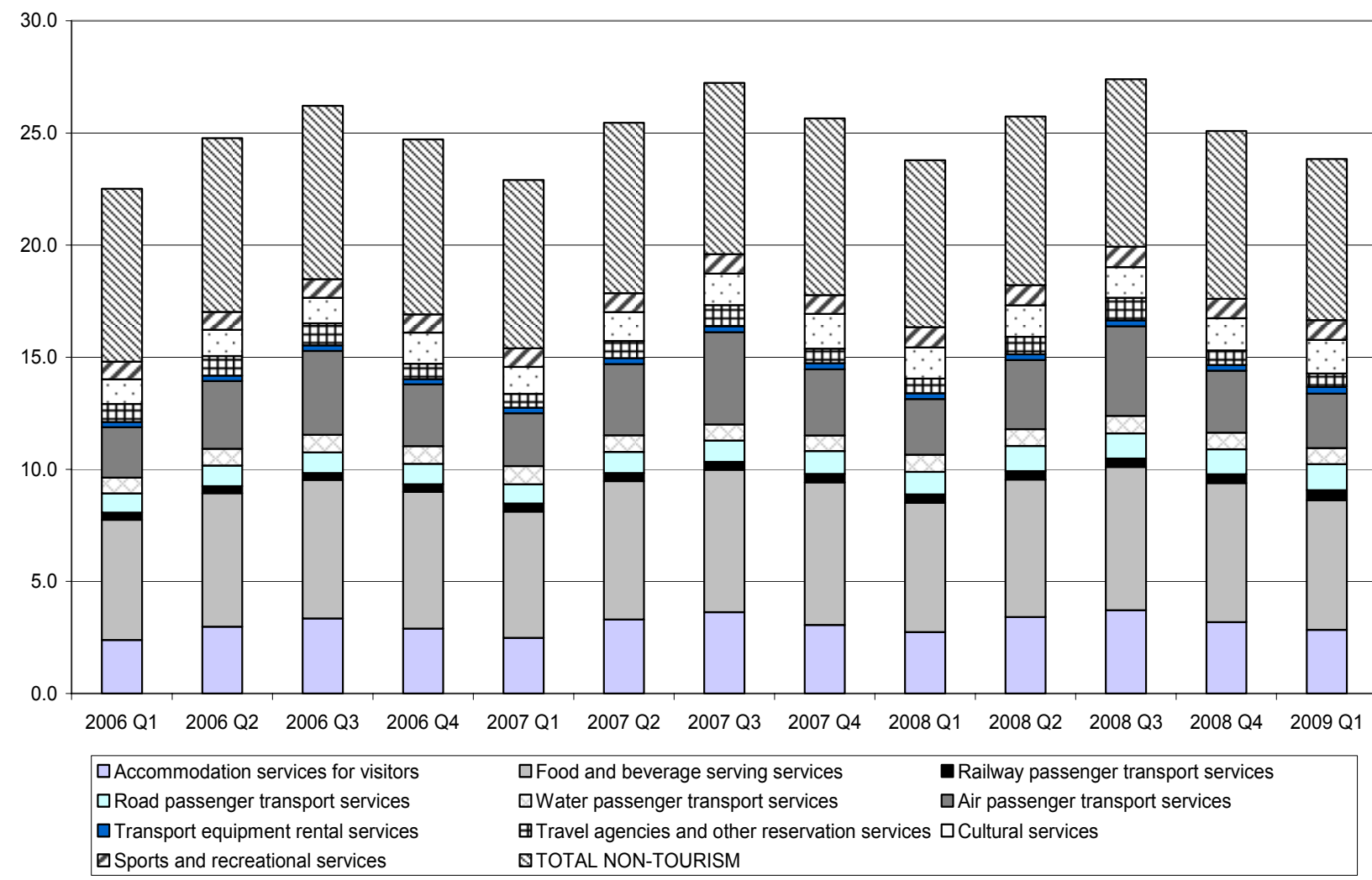

\begin{tabular}{|c|c|c|c|c|c|c|c|c|c|c|c|c|c|}
\hline & $\begin{array}{l}\text { Accommodation } \\
\text { services for } \\
\text { visitors }\end{array}$ & $\begin{array}{l}\text { Food and } \\
\text { beverage } \\
\text { serving } \\
\text { services }\end{array}$ & $\begin{array}{l}\text { Railway } \\
\text { passenger } \\
\text { transport } \\
\text { services }\end{array}$ & $\begin{array}{l}\text { Road } \\
\text { passenger } \\
\text { transport } \\
\text { services }\end{array}$ & $\begin{array}{l}\text { Water } \\
\text { passenger } \\
\text { transport } \\
\text { services }\end{array}$ & $\begin{array}{c}\text { Air } \\
\text { passenger } \\
\text { transport } \\
\text { services }\end{array}$ & $\begin{array}{l}\text { Transport } \\
\text { equipment } \\
\text { rental } \\
\text { services }\end{array}$ & $\begin{array}{c}\text { Travel } \\
\text { agencies and } \\
\text { other } \\
\text { reservation } \\
\text { services }\end{array}$ & $\begin{array}{l}\text { Cultural } \\
\text { services }\end{array}$ & $\begin{array}{l}\text { Sports and } \\
\text { recreational } \\
\text { services }\end{array}$ & $\begin{array}{l}\text { TOTAL } \\
\text { TOURISM }\end{array}$ & $\begin{array}{l}\text { TOTAL } \\
\text { NON- } \\
\text { TOURISM }\end{array}$ & $\begin{array}{c}\text { TOTAL } \\
\text { DEMAND }\end{array}$ \\
\hline 2006 Q1 & 2.4 & 5.4 & 0.3 & 0.9 & 0.7 & 2.3 & 0.2 & 0.8 & 1.1 & 0.8 & 14.8 & 7.7 & 24.1 \\
\hline 2006 Q2 & 3.0 & 6.0 & 0.3 & 0.9 & 0.7 & 3.0 & 0.2 & 0.9 & 1.2 & 0.8 & 17.0 & 7.7 & 24.4 \\
\hline 2006 Q3 & 3.3 & 6.2 & 0.3 & 0.9 & 0.8 & 3.7 & 0.2 & 1.0 & 1.1 & 0.8 & 18.5 & 7.7 & 24.5 \\
\hline 2006 Q4 & 2.9 & 6.1 & 0.3 & 0.9 & 0.8 & 2.8 & 0.2 & 0.7 & 1.4 & 0.8 & 16.9 & 7.8 & 25.2 \\
\hline 2007 Q1 & 2.5 & 5.6 & 0.4 & 0.9 & 0.8 & 2.4 & 0.2 & 0.6 & 1.2 & 0.8 & 15.4 & 7.5 & 24.8 \\
\hline 2007 Q2 & 3.3 & 6.2 & 0.4 & 0.9 & 0.8 & 3.2 & 0.3 & 0.8 & 1.3 & 0.8 & 17.9 & 7.6 & 25.1 \\
\hline 2007 Q3 & 3.6 & 6.4 & 0.3 & 0.9 & 0.7 & 4.1 & 0.3 & 0.9 & 1.4 & 0.9 & 19.6 & 7.6 & 25.3 \\
\hline 2007 Q4 & 3.1 & 6.4 & 0.4 & 1.0 & 0.7 & 3.0 & 0.3 & 0.6 & 1.6 & 0.8 & 17.8 & 7.9 & 26.0 \\
\hline 2008 Q1 & 2.7 & 5.8 & 0.4 & 1.0 & 0.8 & 2.5 & 0.3 & 0.7 & 1.4 & 0.9 & 16.3 & 7.4 & 25.4 \\
\hline 2008 Q2 & 3.4 & 6.1 & 0.4 & 1.1 & 0.7 & 3.1 & 0.3 & 0.8 & 1.4 & 0.9 & 18.2 & 7.5 & 25.6 \\
\hline 2008 Q3 & 3.7 & 6.4 & 0.4 & 1.1 & 0.8 & 4.0 & 0.3 & 1.0 & 1.4 & 0.9 & 19.9 & 7.5 & 25.5 \\
\hline 2008 Q4 & 3.2 & 6.2 & 0.4 & 1.1 & 0.7 & 2.8 & 0.3 & 0.7 & 1.4 & 0.9 & 17.6 & 7.5 & 25.5 \\
\hline 2009 Q1 & 2.8 & 5.8 & 0.4 & 1.2 & 0.7 & 2.4 & 0.3 & 0.6 & 1.5 & 0.9 & 16.7 & 7.2 & 24.2 \\
\hline
\end{tabular}

Source: E-UKTSA 


\section{Conclusions}

The main purpose of this paper was to present a methodology which derives up-to-date figures for the main components of both the demand and supply of tourism. While for the supply side a good set of data sources can be relied on for the demand side some of the time series components have had to be estimated. At this stage, the period starting from the reference date of the E-UKTSA which is 2006 until the first quarter of 2009 has been covered. The estimated figure for the total demand of tourism has increased from $£ 98 \mathrm{bn}$ in 2006, to $£ 101$ billion in 2007 and $£ 102$ billion in 2008. Furthermore the paper has shown how the results of the E-UKTSA can be applied to estimate the level of tourism demand across the various tourism industries. This provides an insight into the seasonal nature of demand and how this translates across the various industries related to the tourism sector.

\section{Notes}

1. As opposed to forecasting, nowcasting implies estimation of current values of variables for which there is a natural lag.

2. UK Tourism Satellite Account - First Steps Projects, prepared by the Cardiff Business School. 3. Table 3 can be considered of secondary importance in that it does not contribute to the determination of the national tourism demand to supply ratio.

\section{Contact}

elmr@ons.gov.uk

\section{References}

Buccellato T, Webber D, and White S (2010) 'The Experimental Tourism Satellite Account for the United Kingdom (E-UKTSA)', Economic \& Labour Market Review (October), available at: www.statistics.gov.uk/elmr/10_10/

Webber D, Buccellato T and White S (2010) 'The global recession and its impact on tourists' spending in the UK', Economic \& Labour Market Review (August), available at: www.statistics.gov.uk/CCl/article.asp? ID $=2554$

\section{Acknowledgements}

We are grateful to Chris Jackson from Statistics Canada for extremely valuable suggestions and advice offered to improve the present work. Furthermore, we would like to thank Calvin Jones, Felix Ritchie and Eddie Smith for their useful contributions to this piece of work. 